\title{
Dysmorphic Concern Questionnaire: Greek Translation, Validation and Psychometric Properties
}

\author{
Fotini Kapsali1 ${ }^{*}$, Pantelis Nikolaou², Charalabos Papageorgiou ${ }^{3,4}$ \\ ${ }^{1}$ Psychiatric Hospital of Attika, Athens, Greece \\ ${ }^{2}$ National and Kappodistrian University of Athens, School of Dentistry, Clinic of Orofacial Pain and Stomatognathic Physiology, \\ Athens, Greece \\ ${ }^{3}$ National and Kappodistrian University of Athens, School of Medicine, Eginition Hospital, First Department of Psychiatry, Athens, \\ Greece \\ ${ }^{4}$ University Mental Health Research Institute, Athens, Greece \\ Email: *fotini_kapsali@hotmail.com
}

How to cite this paper: Kapsali, F., Nikolaou, P. and Papageorgiou, C. (2020) Dysmorphic Concern Questionnaire: Greek Translation, Validation and Psychometric Properties. Open Journal of Psychiatry, 10, 101-113.

https://doi.org/10.4236/ojpsych.2020.103011

Received: April 8, 2020

Accepted: May 10, 2020

Published: May 13, 2020

Copyright $\odot 2020$ by author(s) and Scientific Research Publishing Inc. This work is licensed under the Creative Commons Attribution International License (CC BY 4.0).

http://creativecommons.org/licenses/by/4.0/ (c) (i) Open Access

\begin{abstract}
Aim of this study is to assess the reliability, validity and psychometric properties of the Greek language version of the Dysmorphic Concern Questionnaire (DCQ). Method: The Greek language version of the DCQ scale was presented to 88 healthy individuals ( 57 women and $31 \mathrm{men}$ ) and 32 subjects suffering from body dysmorphic disorder BDD (20 women and 12 men) matched for age and sex. All the BDD group subjects and 57 subjects from the healthy individual group were also assessed according to the following psychometric scales: Symptom Checklist-90-R (SCL-90) scale, Eysenck Personality Questionnaire (EPQ), State-Trait Anxiety Inventory (STAI 1 and STAI -2) and the Zung Self-Rating Depression scales. Results: Regarding the DCQ scale, the analysis revealed that one single factor was extracted that accounted for $71.4 \%$ of the total variance. Cronbach's alpha was 0.933 , indicating a high level of internal consistency. Comparison between groups, healthy individuals vs BDD patients, showed statistically significant differences in almost every item of the SCL-90 scale ( $\mathrm{p}<0.05)$. The Spearman correlations of DCQ score, the DCQ factor score and DCQ T factor with SCL-90, EPQ, as well as the ZUNG depressive scales present high correlation with most items of SCL-90 and ZUNG and STAI-2 ( $<$ 0.005). Conclusion: The Greek version of the Dysmorphic Concern Questionnaire (DCQ) is a valid and reliable instrument, appropriate for both research and clinical settings where dysmorphic concern or body image is a variable which needs to be measured or screened for.
\end{abstract}

\section{Keywords}

Body Dysmorphic Disorder, Reliability, Validity, Body Dysmorphic Concern 


\section{Introduction}

Body dysmorphic disorder (BDD), classified in DSM-5's new chapter of Obsessive-Compulsive and Related Disorders is characterized by distress and excessive preoccupation with one or more perceived defects or flaws in appearance that are not observable or appear only slight to others [1]. At some point during the disorder, repetitive behaviors or mental acts are performed in response to the appearance related preoccupations (e.g., mirror checking, skin picking, excessive grooming, comparing with others) [1]. Patients can become preoccupied with any aspect of appearance, but the most common concerns relate to facial features, including the nose face, eyes, skin and hair. The preoccupations are very time consuming (occurring on average $3-8 \mathrm{~h}$ a day) and usually difficult to resist or control [2].

Although, BDD is a relatively common disorder, with a prevalence in the general population of $1.7 \%-2.4 \%$ [3] [4]: $2.6 \%-16 \%$ among psychiatric patients [5] [6] and 7\% - 14\% in cosmetic surgery and dermatology settings [7] [8], yet is under diagnosed. The disorder typically follows a chronic course and is associated with marked functional impairment, including poor quality of life with social dysfunction, unemployment and reduced academic performance. High comorbidity with major depressive disorder, social anxiety disorder and obsessive-compulsive disorder, is frequently reported [9]. Patients with severe symptoms exhibit high suicidal ideation $(17 \%-80 \%)$ and suicide attempt rates $(24 \%)$ [9]. Individuals with BDD are four times more likely to experience suicidal ideation and 2.6 times more likely to engage in suicidal attempts compared to individuals without BDD [9] [10]. However, increased efforts have focused on understanding the phenomenology, aetiology and treatment of the disorder [11].

Despite increased research interest in DSM-5 defined BDD, it remains clinically under-recognized, partly because many patients pursue surgical, dermatological, and other non-psychiatric treatment and are too ashamed and embarrassed to reveal their concerns or seek psychiatric help [11] [12]. Furthermore, comorbidity between BDD and other disorders indicates that when patients consult mental health professionals they may present with symptoms of depression, social phobia or obsessive-compulsive disorder (OCD), without mentioning symptoms of BDD. Thus, clinicians should inquire directly about symptoms to make the diagnosis [13] [3] [14].

In addition, Dysmorphic concern is a much broader construct than body dysmorphic disorder, that involves symptoms reflecting an overconcern with slight or imagined flaws in appearance [1], that causes subjective distress and leads to impairment in work and social functioning [15]. High levels of dysmorphic concern are common in patients with BDD [16] and among individuals with other disorder such as eating disorders and obsessive-compulsive disorder [17].

BDD patients, as well as individuals with body dysmorphic concern, commonly seek cosmetic treatments in an attempt correct their perceived appear- 
ance defect, with $33 \%$ - 76\% of patients undergoing surgical and invasive cosmetic treatments which are typically associated with negative outcomes, persistent or worsening BDD symptoms [18] [19] [8]. The features of BDD are broadly similar in males and females but evidence suggests that males are more likely to be preoccupied with their genitals and thinning hair, while females are more likely to be preoccupied with hips, breasts, legs and excessive body hair. Thus, clinicians should be aware of potential differences in the clinical presentation of BDD in males and females [20].

The study of dysmorphic concern has received little research attention. One reason for this is the lack of psychometric instruments to assess symptomatology and identify BDD proneness or risk, especially among young people, in general population. Thus, it is important to have adequate ways of screening for dysmorphic concern in order to implement appropriate treatment strategies. The DCQ questionnaire was constructed by Oosthuizen et al. (1998) [15], based on the "General Health Questionnaire" [21]. The questionnaire comprises seven questions relating to appearance concerns. The items are rated on a 4-point scale with $0=$ "not at all", 1 = "like most other people", 2 = "more than other people" and $3=$ "much more than other people". The original version of the DCQ was validated in a sample of 63 psychiatric inpatients diagnosed with schizophrenia or mood disorders. The questionnaire had satisfactory internal consistency and a strong correlation with distress and impairment in several life domains and with Beck Depression Inventory. Validation of DCQ questionnaire in a sample of 2053 participants in the general German population [22] and 966 participants in Spanish population [23], showed also satisfactory validity properties.

There is a pressing need to increase awareness of this serious condition and to promote detection, diagnosis and treatment. Accurate diagnosis of BDD in primary and secondary care settings can be greatly aided by use of brief screening instruments.

The DCQ questionnaire was found to be a reliable and valid instrument that is sensitive to dysmorphic concern. Negative body beliefs are the hallmark of BDD. However, the existence of dysmorphic concern does not necessarily imply a diagnosis of BDD but a broad dimensional construct. The DCQ is a quick and efficient means of identifying dysmorphic concern in those who present with depression, $\mathrm{OCD}$, social phobia or BDD, without seeking to establish a diagnosis of BDD.

Aim of this study is to translate, culturally adapt and validate the DCQ Questionnaire for Greece. Internal consistency, convergent and discriminant validity have also been adapted to fit the Greek version of the instrument.

\section{Method}

In order to develop a Greek version of DCQ, the questionnaire was translated in Greek by two psychiatrists. Then, the Greek version of DCQ questionnaire was back-translated by a person who did not have any knowledge about the origi- 
nal questionnaire or purpose of the study or the original English version. The back-translated version was reviewed in order to establish whether is consistent with the original English version and thus the final Greek version of DCQ questionnaire obtained.

Permission to translate and validate instrument was obtained from Professor David Castle, senior author of the original version of the DCQ questionnaire.

Written inform consent was obtained from all participants.

\subsection{Study Procedure}

The scale was administered to 88 healthy subjects controls came from random sample among general population: 57 women (mean age $32.42 \pm 10.967$ years, range 19 - 55, mean DCQ score $8.45 \pm 3.803$, range 0 - 17) and 31 men (mean age $32 \pm 7.229$ years, range $22-44$, mean DCQ score $6.35 \pm 3.76$, range $0-12$ ) (Table 1).

57 subjects from the 88 healthy individuals: 39 women (mean age $30.82 \pm 10.9$, range 19 - 53) and 18 men (mean age $32.27 \pm 7.23$, range 22 - 43) completed also: SCL-90 scale, EPQ, STAI 1, STAI-2, ZUNG scales. Clinical interview confirmed that they did not suffer from BDD or any other mental disorder.

In addition, the scale was administered to 32 subjects with $\mathrm{BDD}$, treated as outpatients: 20 women (mean age $31.65 \pm 7.909$ years, range 20 - 49) and 12 men (mean age $29 \pm 7.261$ years, range $20-39$ ). When considering the severity of symptoms, the mean DCQ score was for women $13.94 \pm 4.812$ and for men $14.54 \pm 3.98$. BDD was diagnosed according to DSM- 5 criteria for the disorder during a detailed clinical interview by two psychiatrists (Table 1). All patients completed also SCL-90, EPQ, STAI-1, STAI-2 and ZUNG scales.

Eysenck Personality Questionnaire (EPQ) is a questionnaire to assess the personality traits of a person. The Eysenck personality questionnaire consists of 84 items evaluated by the patient with a yes or no. The purpose of this questionnaire is to explore four dimensions of personality: psychoticism (P), neuroticism (N) extraversion (E) and lying (L) [24] [25].

The Symptom Checklist-90-R (SCL-90-R) is a relatively brief self report psychometric instrument, designed to evaluate a broad range of psychological problems and symptoms. The primary symptom dimensions that are assessed are: 1) somatization, 2) obsessive-compulsive, 3) interpersonal sensitivity, 4) depression, 5) anxiety 6) hostility, 7) phobic anxiety, 8) paranoid ideation and 9) psychoticism. The questionnaire includes 90 questions in total. All entries are

Table 1. Sample demographics.

\begin{tabular}{ccccc}
\hline & & N & Age Mean \pm SD & DCQ Mean \pm SD \\
\hline \multirow{2}{*}{ BDD } & Men & 12 & $29 \pm 7.261$ & $14.54 \pm 3.98$ \\
& Women & 20 & $31.65 \pm 7.909$ & $13.94 \pm 4.812$ \\
Healthy subjects & Men & 31 & $32 \pm 7.229$ & $6.35 \pm 3.76$ \\
& Women & 57 & $32.42 \pm 10.967$ & $8.45 \pm 3.803$ \\
\hline
\end{tabular}


rated from 0 to 4 , giving a total score of 360 . The scale is used to extrapolate 3 aggregate indexes: 1) the general gravity index, 2) the positive symptoms distress index, iii) the set of positive symptoms [26] [27].

The Zung Self-Rating Depression Scale is a 20 -item self-report questionnaire that is widely used as a screening tool, covering affective, psychological and somatic symptoms associated with depression. Each item is scored on a Likert scale ranging from 1 to 4 . A total score is derived by summing the individual item scores and ranges from 20 to 80 [28] [29].

The State-Trait Anxiety Inventory (STAI) is an instrument that quantifies adult anxiety. This particular instrument is used to simplify the separation between state anxiety and trait anxiety, feelings of anxiety and depression [30] [31]. It can be used in clinical settings to diagnose anxiety and to distinguish it from depressive syndromes. STAI includes a 40 question response taking approximately 10-20 minutes for completion. This test is split into the S-Anxiety scale and the T-Anxiety scale, each having 20 items.

A weighted Greek version of all scales is available.

\subsection{Statistical Analysis}

All statistical analyses were carried out with STATISTIKA 12.5 STATSOFT. INC and we use $5 \%$ significant levels for all statistical.

Internal consistency reliability of the instrument was evaluated with Cronbach's alpha coefficient.

The contribution of each item to the total score was evaluated with Spearman Rank Order correlations, that also use for evaluation of convergent and discriminant validity, that is the relationship between DCQ score, DCQ one factor, DCQ T weighted factor and scores of other scales (SCL-90, EPQ, ZUNG, STAI-1, STAI-2).

Principal component factor analysis, unrotated, was conducted. The number of factors was based on an examination of eigenvalues greater than 1 .

Differences between two groups (subjects without BDD diagnosis and patients with BDD) were examined using a non-parametric test (Man-Whitney U test) and applying the Bonferroni criterion, as most of variables involved did not meet the homogeneity criterion. $\mathrm{p}$ value of 0.05 was used to determine statistical significance.

In order to further investigate the ability DCQ scale to differentiate between Body dysmorphic patients and healthy controls, we used the MedCalc software to perform ROC analysis using the DCQ raw score as well as the corresponding factor score, i.e. the DCQ single factor score.

\section{Results}

Kayser-Meyer-Olkin Measure of Sampling Adequacy is 0.894, Barlett's test of Sphericity 373.318, $\mathrm{p}<0.0001$, rejecting the null hypothesis that the correlation matrix is an identity matrix. Taken together, these tests provide a minimum 
standard which should be passed before a factor analysis (or a principal components analysis) should be conducted.

Factor analysis (principal components, unrotated) that was performed on 88 healthy individuals, replicated the findings of Oosthuizen et al. (1998), in terms of structure. One single factor was extracted that accounted for $71.4 \%$ of the total variance (Table 2). All items were included.

Cronbach's alpha was 0.933 indicating a high level of internal consistency (0.88 in the original paper) (Table 3 ).

Table 4 presents the value that Cronbach's alpha would be if that particular item was deleted from the scale. We can see that removal of any question, would result in a lower Cronbach's alpha. Therefore, we would not want to remove any item.

In order to investigate the criterion based validity of the DCQ scale, we compare it with scales: SCL-90, EPQ, ZUNG and STAI. The DCQ scale, it's a single factor, and DCQ single factor-T, presents highly correlation with most items of SCL-90 and ZUNG and STAI-2 $(\mathrm{p}<0.005)$.

Comparison between groups (healthy individuals and BDD patients), revealed

Table 2. Factor loadings after factor analysis (varimax, no rotation).

\begin{tabular}{cc}
\hline Variable & $\begin{array}{c}\text { Factor Loadings (Unrotated) } \\
\text { Extraction: Principal Components } \\
\text { Factor 1 }\end{array}$ \\
\hline Concern about physical appearance & -0.782 \\
Consider oneself malformed & -0.783 \\
Consider oneself dysfunctional & -0.793 \\
Consult plastic surgeon & -0.727 \\
Confirmation normality by others & -0.895 \\
Spent time worrying about a defect & -0.922 \\
Spent time covering defects & -0.886 \\
Explained Variance & 4.999 \\
Proportion of Total variance & 0.714 \\
\hline
\end{tabular}

Table 3. Cronbach's alpha if item deleted.

\begin{tabular}{ccccc}
\hline & $\begin{array}{c}\text { Mean if } \\
\text { Deleted }\end{array}$ & $\begin{array}{c}\text { St Dv. if } \\
\text { Deleted }\end{array}$ & $\begin{array}{c}\text { Itm-Totl } \\
\text { Correl }\end{array}$ & $\begin{array}{c}\text { Alpha if } \\
\text { Deleted }\end{array}$ \\
\hline Concern about physical appearance & 7.700 & 4.525 & 0.775 & 0.923 \\
Consider oneself malformed & 8.133 & 4.647 & 0.687 & 0.931 \\
Consider oneself dysfunctional & 8.166 & 4.666 & 0.711 & 0.929 \\
$\quad$ Consult plastic surgeon & 7.991 & 4.546 & 0.737 & 0.927 \\
Confirmation normality by others & 7.991 & 4.443 & 0.839 & 0.917 \\
Spent time worrying about a defect & 7.891 & 4.339 & 0.894 & 0.911 \\
Spent time covering defects & 8.025 & 4.452 & 0.845 & 0.916 \\
\hline
\end{tabular}


Table 4. Spearman correlations of DCQ score, DCQ factor score and DCQ T factor with SCL-90, EPQ, and ZUNG scales.

\begin{tabular}{|c|c|c|c|c|c|c|c|}
\hline & \multirow{3}{*}{$\mathbf{N}$} & DCO Score & \multirow{3}{*}{$\mathrm{p}$} & \multirow{3}{*}{$\begin{array}{c}\text { DCQ } \\
\text { Single Factor } \\
\text { Spearman } \mathrm{R}\end{array}$} & \multicolumn{3}{|c|}{ DCQ T } \\
\hline & & De sedit & & & $\mathrm{p}$ & Factor & $\mathrm{p}$ \\
\hline & & Spearman $\mathbf{R}$ & & & & Spearman $\mathbf{R}$ & \\
\hline SCL-90 index & 87 & 0.533 & 0.001 & -0.268 & 0.011 & -0.268 & 0.011 \\
\hline SCL-90 sum of positive & 87 & 0.503 & 0.001 & -0.250 & 0.019 & -0.250 & 0.019 \\
\hline SCL-90 preoccupation & 87 & 0.413 & 0.001 & -0.134 & 0.215 & -0.134 & 0.215 \\
\hline SCL-90 somatization & 87 & 0.352 & 0.001 & -0.274 & 0.010 & -0.274 & 0.010 \\
\hline SCL-90 obsessive-compulsive & 87 & 0.439 & 0.001 & -0.234 & 0.029 & -0.234 & 0.029 \\
\hline SCL-90 interpersonal sensitivity & 87 & 0.561 & 0.001 & -0.282 & 0.008 & -0.282 & 0.008 \\
\hline SCL-90 depression & 87 & 0.463 & 0.001 & -0.224 & 0.036 & -0.224 & 0.036 \\
\hline SCL-90 anxiety & 87 & 0.453 & 0.001 & -0.171 & 0.112 & -0.171 & 0.112 \\
\hline SCL-90 hostility & 87 & 0.414 & 0.001 & -0.215 & 0.045 & -0.215 & 0.045 \\
\hline SCL-90 phobic anxiety & 87 & 0.440 & 0.002 & -0.243 & 0.022 & -0.243 & 0.022 \\
\hline SCL-90paranoid ideation & 87 & 0.452 & 0.001 & -0.233 & 0.029 & -0.233 & 0.029 \\
\hline SCL-90 psychoticism & 87 & 0.443 & 0.001 & -0.170 & 0.114 & -0.170 & 0.114 \\
\hline STAI-1 & 86 & 0.437 & 0.001 & -0.129 & 0.235 & -0.129 & 0.235 \\
\hline STAI-2 & 86 & 0.570 & 0.001 & -0.288 & 0.007 & -0.288 & 0.007 \\
\hline EPQ_P & 87 & 0.223 & 0.003 & -0.071 & 0.512 & -0.071 & 0.512 \\
\hline EPQ_N & 87 & 0.449 & 0.001 & -0.203 & 0.059 & -0.203 & 0.059 \\
\hline EPQ_E & 87 & -0.199 & 0.063 & 0.071 & 0.511 & 0.071 & 0.511 \\
\hline EPQ_L & 87 & -0.135 & 0.209 & 0.083 & 0.440 & 0.083 & 0.440 \\
\hline ZUNG & 85 & 0.511 & 0.001 & -0.234 & 0.030 & -0.234 & 0.030 \\
\hline
\end{tabular}

statistically significant differences, in almost every item of SCL-90 scale $(\mathrm{p}<$ 0.05). Patients with BDD had higher score in almost every item of SCL-90 scale, than healthy group (Table 5).

More specifically the raw DCQ score had sensitivity 59.38 and specificity 88.64 at a cut-off point $>12$ whereas the BDS single factor score had sensitivity 78.12 and specificity 52.27 at a cut-off point of $\leq 0.19$.

As can be seen in Figure 1, the raw DCQ score was better in differentiating between Body Dysmorphic patients and healthy controls than the single DCQ factor score the control group with area under curve (AUC) 0.754 as opposed to 0.573 .

More specifically the raw DCQ score had sensitivity 59.38 and specificity 88.64 at a cut-off point $>12$ whereas the BDS single factor score had sensitivity 78.12 and specificity 52.27 at a cut-off point of $\leq 0.19$.

\section{Discussion}

DCQ is a specific instrument, as a screening tool for Body Dysmorphic Concern. The questionnaire assesses overconcern about physical appearance without 
Table 5. Comparison between subjects with BDD and healthy individuals

\begin{tabular}{|c|c|c|c|c|c|c|}
\hline Man-Whitney U-Test & $\begin{array}{c}\text { Rank Sum } \\
\text { Controls }\end{array}$ & $\begin{array}{c}\text { Rank Sum } \\
\text { BDD }\end{array}$ & $\mathrm{U}$ & $\mathrm{Z}$ & $\mathrm{p}$ & $\begin{array}{c}\mathrm{p} \text { (after } \\
\text { Bonferroni } \\
\text { Correction) }\end{array}$ \\
\hline DCQ single T-factor & 5535.500 & 1724.500 & 1196.500 & 1.252 & 0.209 & 3.14 \\
\hline SCL-90 Index & 2049.000 & 1779.000 & 396.000 & -4.094 & 0.001 & 0.01 \\
\hline SCL-90 Sum of positive & 2125.500 & 1702.500 & 472.500 & -3.411 & 0.001 & 0.01 \\
\hline SCL90 Preoccupation & 2241.500 & 1586.500 & 588.500 & -2.375 & 0.017 & 0,26 \\
\hline SCL90 Somatization & 2250.000 & 1578.000 & 597.000 & -2.299 & 0.021 & 0.32 \\
\hline SCL-90 Obsessive compulsive & 2127.500 & 1700.500 & 474.500 & -3.393 & 0.001 & 0.01 \\
\hline SCL-90 Interpersonal sensitivity & 2143.000 & 1685.000 & 490.000 & -3.254 & 0.001 & 0.02 \\
\hline SCL-90 Depression & 2070.000 & 1758.000 & 417.000 & -3.906 & 0.001 & 0.00 \\
\hline SCL-90 Anxiety & 2117.000 & 1711.000 & 464.000 & -3.487 & 0.001 & 0.01 \\
\hline SCL-90 Hostility & 2170.000 & 1658.000 & 517.000 & -3.013 & 0.002 & 0.04 \\
\hline SCL-90 Phobic anxiety & 2003.500 & 1824.500 & 350.500 & -4.500 & 0.001 & 0.00 \\
\hline SCL-90 Paranoid ideation & 2170.000 & 1658.000 & 517.000 & -3.013 & 0.002 & 0.03 \\
\hline SCL-90 Psychoticism & 2154.000 & 1674.000 & 501.000 & -3.15 & 0.001 & 0.02 \\
\hline
\end{tabular}

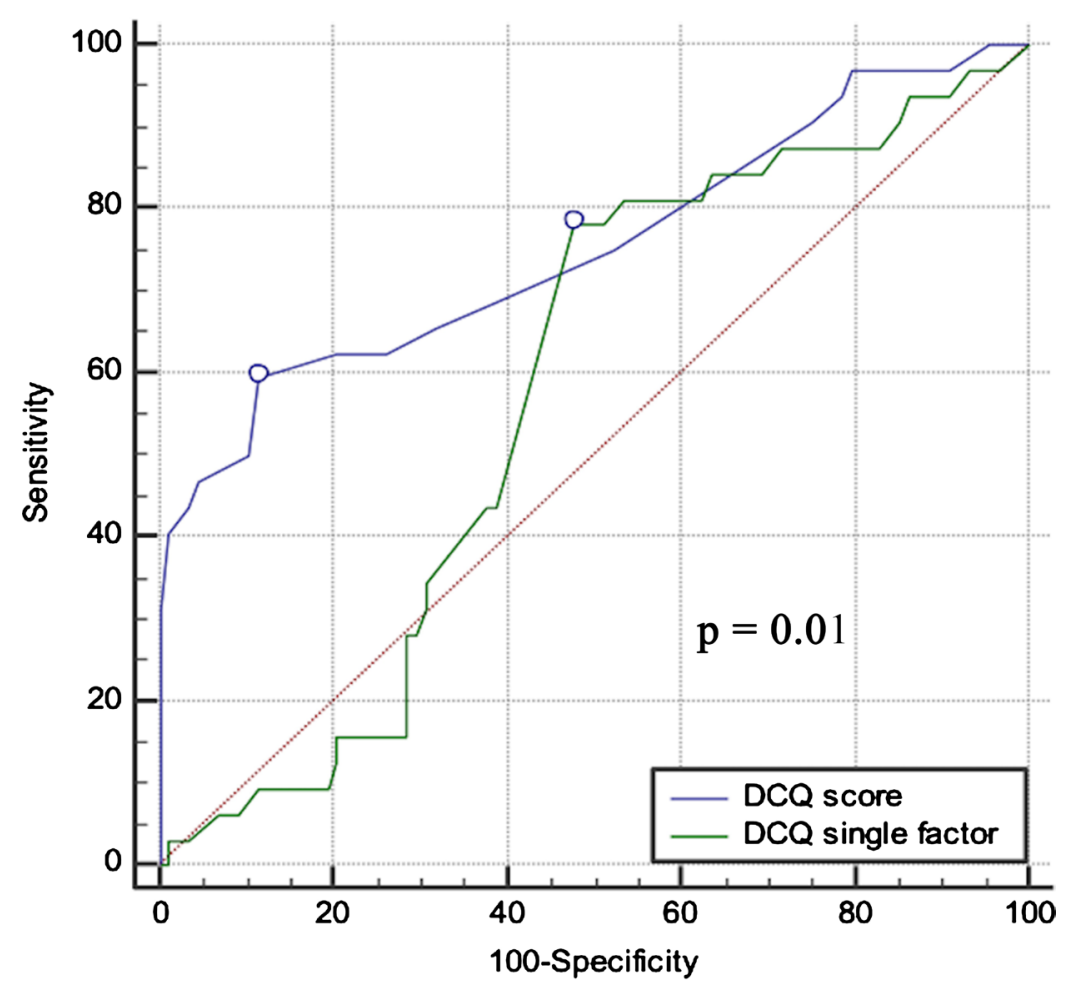

Figure 1. Receiver operating characteristic (ROC) curve for the Greek version of the Dysmorphic Concern Questionnaire. 
establishing a diagnosis of BDD. The current study reports observations on the reliability, the validity and psychometric properties of the Greek language version of the DCQ questionnaire.

The translation process was relatively straightforward with no differences between the original and the back-translated version of the questionnaire.

The Greek version of the DCQ was validated on a non psychiatric control group of 88 healthy subjects and 32 patients with BDD disorder.

The Greek version of the DCQ questionnaire, shows excellent internal consistency with a Cronbach's alpha coefficient of 0.933 , compared to 0.88 for the original measure.

The factor analysis (principal components, unrotated) replicated the findings of Oosthuizen et al (1998) [15], in terms of structure. One single factor was extracted that accounted for $71.4 \%$ of the total variance (Table 1), instead of $58.4 \%$ of the original version. In German validation, Cronbach's alpha coefficient was 0.81 and one single factor was extracted [22]. In Spanish validation Cronbach's alpha coefficient was 0.82 and also corroborated the one-dimensional structure of the Questionnaire [23].

88 participants ( 57 healthy subjects and $32 \mathrm{BDD}$ patients) were also assessed according to the following scales: SCL-90, EPQ, STAI-1, STAI 2 and the ZUNG scales.

In concordance with the original scale, there was no statistically significant correlation between DCQ total score and the responder's age or sex.

The DCQ questionnaire was positively correlated with the SCL-90 on most items: general index of psychopathology, obsessive-compulsive, interpersonal sensitivity, depression, anxiety, hostility, phobic anxiety, psychoticism $(\mathrm{p}<$ 0.001). The DCQ total score, was also correlated highly with the N, P and low E subscales of the EPQ scale, Zung depression scale, STAI-1 and STAI-2 scales. These findings are in agreement with the results of Oosthuizen et al (1998) [15] results, who found a strong correlation between the DCQ total score and depression (BDI total score), especially on "cognitive items".

The related literature reports the frequent presence of other psychiatric symptoms in patients with BDD, including high prevalence rates of major depression (60\%), in particular atypical depression (14\%) [32] and obsessive-compulsive disorder $(8 \%-37 \%)$.

In this context, Philips et al (2004) [33], assessed symptoms and well being in the fields of depression, anxiety, somatization, and anger/hostility, by using the Symptom Questionnaire and she demonstrated that, compared to normal controls, these patients presented elevated scores on all four scales, indicating severe distress and psychopathology. The most common personality disorders were avoidant, paranoid and obsessive-compulsive, combined to high levels of neuroticism and low levels of extraversion. Mancuso et al, (2009), [34] in a study using the Temperament and Character Inventory (TCI), reported higher harm avoidance scores, higher Novelty Seeking, lower self directedness and coopera- 
tiveness scores, anxiety and anger [34].

The comparison between BDD patients and healthy controls regarding discriminant validity, revealed the existence of statistically significant differences: using Man Whitney U test was used within almost every item of the SCL-90 scale; with patients showed higher scores in: general index of psychopathology, sum of positive symptoms, obsessive-compulsive disorder, interpersonal sensitivity, depression, anxiety, phobic anxiety, hostility, paranoid ideation, psychoticism $(\mathrm{p}<0.05)$. Furthermore, patients with BDD referred severe distress and psychopathology. Interestingly, there were no statistically significant differences between the two groups in the EPQ personality traits scale, STAI-1, STAI-2 anxiety stait-trait scales and ZUNG depression scale.

The DCQ questionnaire is useful for identifying BDD proneness or risk. It could be useful in dermatological and aesthetic surgery settings, to identify patients with BDD seeking treatment or surgery. This is particularly important among young people, as it is known that the first symptoms of BDD start in adolescence at around 16 years of age. Mastro et al., 2016, [35] found that 9\% of young people with a mean age of 12 could be at risk of developing BDD. Although all cases of dysmorphic concern, do not qualify for a formal diagnosis of $\mathrm{BDD}$, this does not mean exemption from distress, and it may define a situation of personal risk.

Limitations of this study include the failure to assess the test-retest reliability and the relatively small patient sample size.

\section{Conclusion}

The Dysmorphic Concern Questionnaire (DCQ questionnaire) is a reliable and valid instrument that is sensitive to dysmorphic concern. In the present study, we aimed to test this model in a sample of Greek population, including both healthy controls and BDD patients. The Greek version of the DCQ questionnaire presents good criterion base validity by showing significant correlations with the SCL-90, Zung, as well as with the STAI-1 \& STAI-2 scales and EPQ scale, yielding a single factor psychometric version. In conclusion, the psychometric strength of DCQ Questionnaire, Greek version, is both reliable and valid and is suitable for clinical settings and research use with satisfactory results.

\section{Acknowledgments}

We would like to acknowledge the support of DHI Hair restoration company for the valuable and constructive contribution to this research project.

\section{Conflicts of Interest}

The authors declare no conflicts of interest regarding the publication of this paper.

\section{References}

[1] American Psychiatric Association (2013) Obsessive-Compulsive and Related Dis- 
orders. In: American Psychiatric Association, Ed., Diagnostic and Statistical Manual of Mental Disorders, Fifth Edition (DSM-5), American Psychiatric Publishing, Arlington, 235-264.

[2] Philips, K., Quinn, G. and Stout, R.L. (2008) Functional Impairment in Body Dysmorphic Disorder: A Prospective, Follow-Up Study. Journal of Psychiatry Research, 42, 701-707. https://doi.org/10.1016/j.jpsychires.2007.07.010

[3] Conroy, M., Menard, W., Fleming-Ives, K., Modha, P., Cerullo, H. and Philips, K. (2008) Prevalence and Clinical Characteristics of Body Dysmorphic Disorder in an Adult Inpatient Setting. General Hospital Psychiatry, 30, 62-77. https://doi.org/10.1016/j.genhosppsych.2007.09.004

[4] Buhlann, E., Krebs, G. and Mataix-Cols, D. (2010) A Critical Review of Cosmetic Treatment Outcomes in Body Dysmorphic Disorder. Psychiatry Research, 178, 171-175.

[5] Kollei, J., Martin, A., Rein, K., Rotter, A., Jaccobi, A. and Mueller, A. (2011) Prevalence of Body Dysmorphic Disorder in a German Psychiatric Inpatient Sample. Psychiatry Research, 189, 153-155. https://doi.org/10.1016/j.psychres.2011.02.009

[6] Zimmerman, M. and Mattia, J. (1998) Body Dysmorphic Disorder in Psychiatric Outpatients; Recognition, Prevalence, Comorbidity, Demographic and Clinical Correlates. Comprehensive Psychiatry, 39, 265-270. https://doi.org/10.1016/S0010-440X(98)90034-7

[7] Uzun, O., Basogilu, C., Akar, A., Cansever, A., Ozsahin, A., Cetin, M. and Ebrine, S. (2003) Body Dysmorphic Disorder in Patients with Acne. Comprehensive Psychiatry, 44, 415-419. https://doi.org/10.1016/S0010-440X(03)00102-0

[8] Philips, K. (2006) The Presentation of Body Dysmorphic Disorder in Medical Settings. Primary Psychiatry, 13, 51-59.

[9] Philips, K. (2007) Suicidality in Body Dysmorphic Disorder. Primary Psychiatry, 14, 58-66.

[10] Angelakis, I., Gooding, P. and Panagioti, P. (2016) Suicidality in Body Dysmorphic Disorder: A Systematic Review with Meta-Analysis. Clinical Psychology Review, 49, 55-66. https://doi.org/10.1016/j.cpr.2016.08.002

[11] Krebs, G., Fernadez de la Cruz, L. and Mataix-Cols, D. (2017) Recent Advances in Understanding and Managing Body Dysmorphic Disorder. Evidence-Based Mental Health, 20, 71-75. https://doi.org/10.1136/eb-2017-102702

[12] Sanwer, D., Crerand, C. and Margee, L. (2010) Body Dysmorphic Disorder in Patients Who Seek Appearance Enhancing Medical Treatments. Oral \& Maxillofacial Surgery Clinics, 22, 445-453. https://doi.org/10.1016/j.coms.2010.07.002

[13] Vindigni, V., Pavan, C., Semenzin, M., Granè, S., Gambaro, F.M. and Marini, M. (2002) The Importance of Recognizing Body Dysmorphic Disorder in Cosmetic Surgery Patients: Do Our Patients Need a Preoperative Psychiatric Evaluation? European Journal of Plastic Surgery, 25, 305-308.

[14] Bowyer, L., Krebs, G. and Mataix-Cols, D. (2016) A Critical Review of Cosmetic Treatment Outcomes in Body Dysmorphic Disorder. Body Image, 19, 1-8. https://doi.org/10.1016/j.bodyim.2016.07.001

[15] Oosthuizen, P., Lambert, C. and Castle, D. (1998) Dysmorphic Concern: Prevalence and Associations with Clinical Variances. Australian and New Zealand Journal of Psychiatry, 32, 129-132. https://doi.org/10.3109/00048679809062719

[16] Philips, K., McElroy, S.L., Keck, P.E., Pope, H.G. and Hudson, J.I. (1993) Body Dysmorphic Disorder: 30 Cases of Imagined Ugliness. American Journal of Psychi- 
atry, 150, 302-308. https://doi.org/10.1176/ajp.150.2.302

[17] Jolanta, J.R.J. and Tomasz, M.S. (2000) The Links between Body Dysmorphic Disorder and Eating Disorders. European Psychiatry, 15, 302-305. https://doi.org/10.1016/S0924-9338(00)00398-9

[18] Castle, D.J. and Morkell, D. (1991) Imagined Ugliness a Symptom Which Can Become a Disorder. Medical Journal of Psychiatry, 148, 1137-1149.

[19] Castle, D., Molton, M., Preston, N. and Philips, K. (2004) Correlates of Dysmorphic Concern in People Seeking Cosmetic Enhancement. Australian \& New Zealand Journal of Psychiatry, 38, 439-444. https://doi.org/10.1080/j.1440-1614.2004.01381.x

[20] Veale, D., Gledhill, L.J. and Christodoulou, P. (2016) Body Dysmorphic Disorder in Different Settings: A Systematic Review and Estimated Weighted Prevalence. Body Image, 18, 168-186. https://doi.org/10.1016/j.bodyim.2016.07.003

[21] Goldberg, D.P. (1972) The Detection of Psychiatric Illness by Questionnaire. Oxford University Press, London.

[22] Shieber, K., Kollei, I., de Zwaan, M. and Martin, A. (2018) The Dysmorphic Concern Questionnaire in the German General Population: Psychometric Properties and Normative Data. Aesthetic Plastic Surgery, 42, 1412-1420. https://doi.org/10.1007/s00266-018-1183-1

[23] Senin-Calderon, C., Valdez-Dias, M., Benitez-Hernadez, M., Nunez-Gaitan, M.C., Perona-Garcelan, S., Martinez-Cervantes, R. and Rodrigez-Testal, J.F. (2017) Validation of Spanish Language Evaluation Instruments for Body Dysmorphic Disorder and the Dysmorphic Concern Construct. Frontiers in Psychology, 8, 1107.

https://doi.org/10.3389/fpsyg.2017.01107

[24] Eysenck, H.J. and Eysenck, S.B.G. (1975) Manual of the EPQ (Personality Questionnaire). Hodder and Stoyghton Educational, London.

https://doi.org/10.1037/t05462-000

[25] Dimitriou, E. (1986) EPQ Personality Questionnaire (1986) Greek Validation in the Greek Population. Engefalos, 23, 41-54.

[26] Derogatis, L. and Melisaratos, N. (1983) The Brief Symptom Inventory: An Introductory Report. Psychological Medicine, 13, 595-605. https://doi.org/10.1017/S0033291700048017

[27] Donias, S., Karastergiou, A. and Manos, N. (1991) Validation of the Symptom Checklist-90-R in Greek Population. Psychiatriki, 2, 42-48.

https://doi.org/10.5431/aramit0209

[28] Zung, W.W.K. (1965) A Self-Rating Depression Scale. Archives of General Psychiatry, 12, 63-70. https://doi.org/10.1001/archpsyc.1965.01720310065008

[29] Fountoulakis, K., Iacivides, A., Samolis, S., Kaprinis, S., Kaprinis, G. and Bech, P. (2006) Reliability, Validity and Psychometric Properties of the Greek Translation of Zung Depression Rating Scale. Annals of General Psychiatry, 5, 2. https://doi.org/10.1186/1744-859X-5-2

[30] Spielberger, C.D., Gorssuch, R.L., Lushene, P.R., Vagg, P.R. and Jacobs, G.A. (1983) Manual for the State-Trait Anxiety Inventory. Consulting Psychologists Press, Palo Alto.

[31] Fountoulakis, K., Papadopoulou, M., Kleanthous, S., Papadopoulou, A., Bizeeli, V., Nimatoudis, I., Iacovidis, A. and Kaprinis, G. (2006) Reliability and Psychometric Properties of the Greek Translation of the State-Trait Anxiety Inventory form Y: Preliminary Data. Annals of General Psychiatry, 5, 2. https://doi.org/10.1186/1744-859X-5-2 
[32] Nierenberg, A.A., Philips, K.A., Petersen, T.J., Kelly, K.E., Alpert, J.E., Worthington, J.J., Tedlow, J.R., Rosenbum, J.P. and Fava, M. (2002) Body Dysmorphic Disorder in Outpatients Major Depression. Journal of Affective Disorders, 69, 141-148. https://doi.org/10.1016/S0165-0327(01)00304-4

[33] Philips, K. (2004) Body Dysmorphic Disorder: Recognizing and Treating Imagined Ugliness. World Psychiatry, 3, 12-17.

[34] Mancuso, S., Knoesen, N., Chamberlain, J., Cloninger, R. and Castle, D. (2009) The Temperament and Character Profile of a Body Dysmorphic Disorder Sample. Personality and Mental Health, 2, 284-294. https://doi.org/10.1002/pmh.81

[35] Mastro, S., Zimmer-Gembeck, M., Webb, H. and Fattell, L. (2015) Young Adolescents' Appearance Anxiety and Body Dysmorphic Symptoms: Social Problems, Self-Perceptions and Comorbidities. Journal of Obsessive-Compulsive and Related Disorders, 8, 50-55. https://doi.org/10.1016/j.jocrd.2015.12.001 